\section{Study of the incorporation and release of the non-conventional half-sandwich ruthenium(II) metallodrug RAPTA-C on a robust MOF $\dagger$}

\author{
Elsa Quartapelle Procopio, ${ }^{a}$ Sara Rojas, ${ }^{a}$ Natalia M. Padial, ${ }^{b}$ Simona Galli, ${ }^{c}$ \\ Norberto Masciocchi, ${ }^{c}$ Fátima Linares, ${ }^{a}$ Delia Miguel, ${ }^{b}$ J. Enrique Oltra, ${ }^{b}$ \\ Jorge A. R. Navarro ${ }^{* a}$ and Elisa Barea ${ }^{* a}$
}

Received 27th July 2011, Accepted 13th September 2011

DOI: $10.1039 / \mathrm{c} 1 \mathrm{cc} 14594 \mathrm{k}$

The highly porous and robust $\left[\mathrm{Ni}_{8}(\mathrm{OH})_{4}\left(\mathrm{OH}_{2}\right)_{2}\left(4,4^{\prime}\right.\right.$-(buta-1,3diyne-1,4-diyl)bispyrazolato $)_{6} \mathrm{I}_{n}$ MOF can be used as a proof of concept for the incorporation and release of the nonconventional [Ru(p-cymene) $\mathrm{Cl}_{2}$ (pta)] $\mathrm{RAPTA-C}$ metallodrug.

In the last few years, the interest in the outperforming adsorptive properties of Metal-Organic Frameworks (MOFs) has been extended from an initial focus on gas storage and purification to the controlled release of bioactive molecules. ${ }^{1}$ Depending on pore nature and size, the bioactive species to be delivered can range from small gaseous molecules (e.g. NO, $\mathrm{CO})$ coordinated to the open metal sites, ${ }^{2}$ to small organic drugs (ibuprofen, ${ }^{3}$ doxorubicin) $)^{4,5}$ physisorbed in the pore structure, or even to metalloligand pro-drugs used as linkers within the MOF itself. ${ }^{6}$

One of the current major social concerns is to find effective treatments to cure cancer. It is well known that the use of $\mathrm{Pt}$ (II)-based cytotoxic metallodrugs is one of the most widespread treatments against cancer. ${ }^{7}$ However, the adverse side effects and the development of resistance are related to the unspecific interactions of $\mathrm{Pt}$ (II) metallodrugs with biomolecules, in particular with the desired biological target, DNA.

Consequently, there is much interest in finding new metallodrugs with a different mechanism of action. A number of halfsandwich type organometallic compounds of $\mathrm{Ru}, \mathrm{Rh}, \mathrm{Ir}$ and Os have emerged as alternative anti-tumour and antimetastatic metallodrugs, exhibiting a different mechanism of action that may lead to fewer adverse side effects. Indeed, it seems that the primary activity of these species does not involve DNA but the inhibition of the exacerbated metabolism of many cancer cell types (i.e. inhibition of over-expressed

\footnotetext{
${ }^{a}$ Universidad de Granada, Departamento de Química Inorganica, 18071 Granada,Spain.E-mail: ebaream@ugr.es; jarn@ugr.es; Fax: + 34958 248526; Tel: + 34958248093

${ }^{b}$ Universidad de Granada, Departamento de Química Organica, 18071 Granada, Spain

${ }^{c}$ Dipartimento di Scienze Chimiche e Ambientali, Università dell'Insubria, 22100 Como, Italy

$\dagger$ Electronic supplementary information (ESI) available: Experimental methods, thermal analysis, chemical stability tests, mechanical stress tests, crystallographic data. CCDC 829304 . For ESI and crystallographic data in CIF or other electronic format see DOI: 10.1039/ clcc14594k
}

enzymes like cathepsines), ${ }^{8}$ or the interference with physiological redox processes. ${ }^{9}$ In this sense, a notable example is the nonconventional metallodrug $\left[\mathrm{Ru}(p\right.$-cymene $\left.) \mathrm{Cl}_{2}(\mathrm{pta})\right]$ (pta $=$ 1,3,5-triaza-7-phospha-adamantane), termed "RAPTA-C" (Fig. 1), which is proved to inhibit lung metastases in mice. ${ }^{10}$ Accordingly, it would be highly beneficial for patients to find methods for the controlled delivery of these novel metallodrugs.

In this communication, we present the synthesis and full characterisation of the highly porous and robust $\left[\mathrm{Ni}_{8}\left(\mu_{4}-\mathrm{OH}\right)_{4}\right.$ $\left.\left(\mu_{4}-\mathrm{OH}_{2}\right)_{2}\left(\mu_{4}-4,4^{\prime} \text {-(buta-1,3-diyne-1,4-diyl)bispyrazolato }\right)_{6}\right]_{n}$ (1) MOF containing a new bispyrazolate type organic linker. Worthy of note, $\mathbf{1}$ shows a remarkable thermal and chemical stability, even in simulated body fluid (SBF). ${ }^{11}$ Moreover, we have studied the incorporation and release of RAPTA-C in 1 as a proof of concept of the utility of MOFs for the delivery of this type of non-conventional metallodrugs.

The key step of the synthesis of the novel organic linker adopted in this study was a $\mathrm{Pd} / \mathrm{Cu}$-catalyzed homocoupling reaction on the boc-protected 4-ethynyl-pyrazole precursor to achieve the symmetric rod-like species $1,1^{\prime}$-di-Boc-4,4'-(buta1,3-diyne-1,4-diyl)bispyrazole (Fig. 1). The posterior reaction of this system with $\mathrm{Ni}(\mathrm{AcO})_{2} \cdot 4 \mathrm{H}_{2} \mathrm{O}$ in boiling aqueous $\mathrm{DMF}$ gave rise to the deprotection of the pyrazolate donor groups,

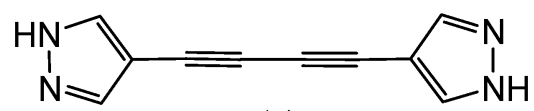

(a)

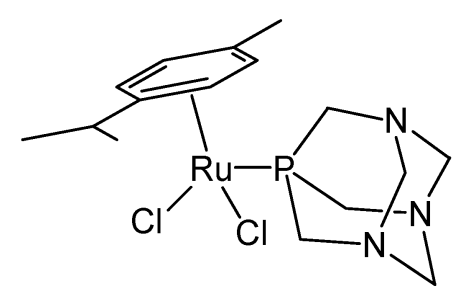

(b)

Fig. 1 (a) The 4,4'-(buta-1,3-diyne-1,4-diyl)bispyrazole linker used in this study; (b) the anti-tumour metallodrug $\left[\mathrm{Ru}(p\right.$-cymene $\left.) \mathrm{Cl}_{2}(\mathrm{pta})\right]$ (pta $=1,3,5$-triaza-7-phospha-adamantane), RAPTA-C, used in the drug delivery process. 

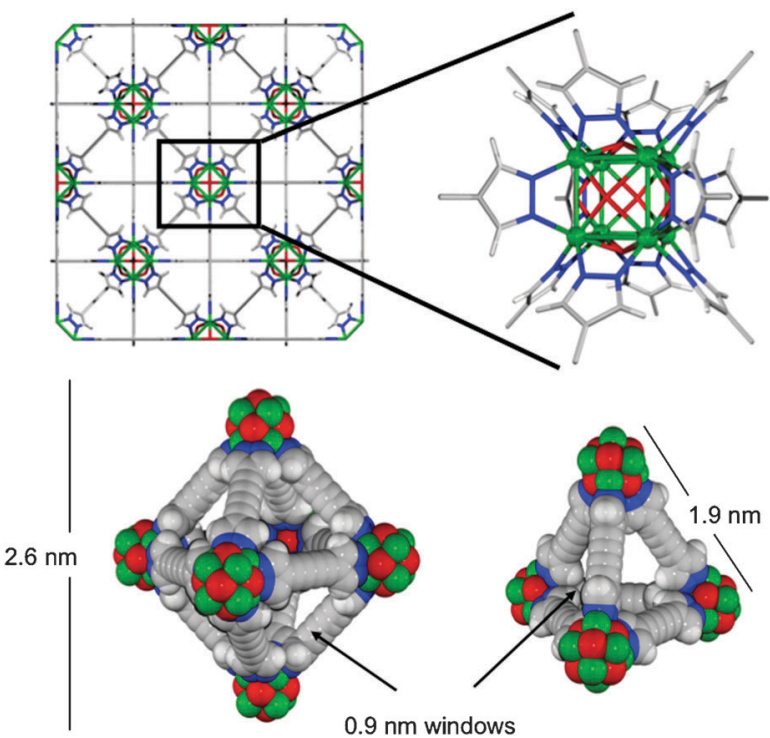

Fig. 2 View of the crystal structure of $\left[\mathrm{Ni}_{8}\left(\mu_{4}-\mathrm{OH}\right)_{4}\left(\mu_{4}-\mathrm{OH}_{2}\right)_{2}-\right.$ $\left(\mu_{4}-4,4^{\prime} \text {-(buta-1,3-diyne-1,4-diyl)bispyrazolato) }\right]_{n}$ (1) along the [100] direction and the magnified view of the 12 -connecting $\mathrm{Ni}_{8}\left(\mu_{4}-\mathrm{OH}\right)_{4^{-}}$ $\left(\mu_{4}-\mathrm{OH}_{2}\right)_{2}$ nodes (above); view of the octahedral and tetrahedral voids found in the crystal structure of $\mathbf{1}$ (below). Ni: green, O: red, N: blue, $\mathrm{C}$ : grey, H: light grey.

yielding a light green microcrystalline material of $\left[\mathrm{Ni}_{8}(\mathrm{OH})_{4}\right.$ $\left.\left(\mathrm{OH}_{2}\right)_{2}\left(4,4^{\prime} \text {-(buta-1,3-diyne-1,4-diyl)bispyrazolato }\right)_{6}\right] \cdot 11 \mathrm{H}_{2} \mathrm{O}$.

$13 \mathrm{C}_{3} \mathrm{H}_{7} \mathrm{NO}\left(\mathbf{1} \cdot \mathbf{H}_{\mathbf{2}} \mathbf{O} \cdot \mathbf{D M F}\right)$ formulation.

An XRPD structural analysis demonstrated that $\mathbf{1} \cdot \mathbf{H}_{\mathbf{2}} \mathbf{O}$. DMF is isomorphous to the $\left[\mathrm{Ni}_{8}\left(\mu_{4}-\mathrm{OH}\right)_{4}\left(\mu_{4}-\mathrm{OH}_{2}\right)_{2}\right.$ $\left.\left(\mu_{4}-\mathrm{L}\right)_{6}\right]_{n}$.nSolv systems previously reported by us. ${ }^{12}$ Accordingly, the structure of $\mathbf{1} \cdot \mathbf{H}_{\mathbf{2}} \mathbf{O} \cdot \mathbf{D M F}$ is based on $\mathrm{Ni}_{8}(\mathrm{OH})_{4}\left(\mathrm{OH}_{2}\right)_{2}$ cubic clusters connected to 12 adjacent ones by linear exotetradentate $N, N, N^{\prime}, N^{\prime} \quad 4,4^{\prime}$-(buta-1,3-diyne-1,4-diyl)bispyrazolato linkers. Noteworthily, this topology, reminiscent of the cubic close packing structure found in many elemental solids, features octahedral and tetrahedral voids of about $1.6 \mathrm{~nm}$ and $1.0 \mathrm{~nm}$ inner size ${ }^{13}$ respectively (Fig. 2). As a consequence of the large voids and the low steric demand of the diyne residues in the organic linker, the calculated accessible pore volume in the structure is very high, reaching $71 \%$ of the total crystal volume.

The thermogravimetric analysis carried out in air on $\mathbf{1} \cdot \mathbf{H}_{\mathbf{2}} \mathbf{O}$. DMF and on the $\mathrm{CH}_{2} \mathrm{Cl}_{2}$ exchanged material $\mathbf{1} \cdot \mathbf{C H}_{\mathbf{2}} \mathbf{C l}_{\mathbf{2}}$ (Fig. S2, ESI $\dagger$ ) shows that, upon removal of the guest solvent molecules, the evacuated structure remains stable up to $340{ }^{\circ} \mathrm{C}$, the temperature after which it undergoes a rapid decomposition. Moreover, 1 also shows a high mechanical stability, its crystallinity and porosity remaining almost unaffected when pressed up to $2 \mathrm{Mg} \mathrm{cm}^{-2}$ (Fig. S4, ESI $\dagger$ ).

$\mathrm{N}_{2}$ adsorption experiments carried out on $\mathbf{1}$ at $77 \mathrm{~K}$ are indicative of a highly porous structure exhibiting a type I isotherm typical of crystalline microporous materials (Fig. 3). The BET surface area of $1920 \mathrm{~m}^{2} \mathrm{~g}^{-1}$ is remarkably high, as it is the adsorption capacity, which reaches the value of $26 \mathrm{mmol} \mathrm{g}^{-1}$ at $p / p_{\mathrm{o}}=0.3$.

Noteworthily, 1 also possesses a remarkably high chemical stability, which is exemplified by the fact that its XRPD remains unaltered up to $24 \mathrm{~h}$ in boiling water and in common organic solvents, in basic ( $\mathrm{NaOH} 0.05 \mathrm{M}, \mathrm{pH} 12.80)$ and acidic

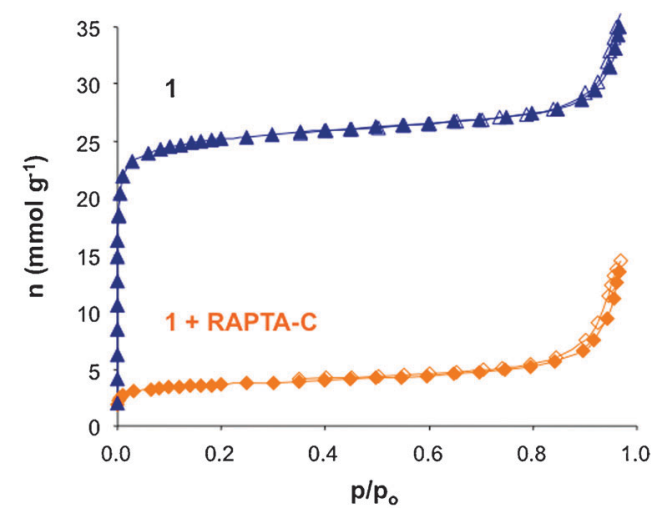

Fig. $3 \mathrm{~N}_{2}(77 \mathrm{~K})$ adsorption isotherms for activated $\left[\mathrm{Ni}_{8}\left(\mu_{4}-\mathrm{OH}\right)_{4}\right.$ $\left(\mu_{4}-\mathrm{OH}_{2}\right)_{2}\left(\mu_{4}-4,4^{\prime} \text {-(buta-1,3-diyne-1,4-diyl)bispyrazolato) }\right]_{n}$ (1) (blue triangles) and the RAPTA-C loaded 1-RAPTA-C product (orange diamonds). Empty symbols denote desorption.

$(\mathrm{HCl} 0.01 \mathrm{M}, \mathrm{pH} 2.30)$ aqueous solutions, as well as in simulated body fluid (SBF) at $37{ }^{\circ} \mathrm{C}(\mathrm{pH} 8.05)$ for 7 days (Fig. S3, ESI $\dagger$ ). The robustness of this material in SBF is proved by means of atomic absorption (AA) measurements, indicating very low Ni leaching. Indeed, suspensions of $\mathbf{1}$ in $\mathrm{SBF}$ at $37^{\circ} \mathrm{C}$ (20 mg of $\mathbf{1} \mathrm{in} 40 \mathrm{~mL}$ of SBF) give rise to $0.7 \mathrm{ppm}$ of Ni concentration levels, which indicate that only $0.43 \%$ of the MOF material has been degraded. This value corresponds to the liberation of $70 \mu \mathrm{g}$ of $\mathrm{Ni}$ per $100 \mathrm{~mL}$ of SBF with suspended 1. It should be noted that this amount is neatly below the daily average uptake of $170 \mu \mathrm{g}$ of $\mathrm{Ni}$ in food. ${ }^{14}$

The stability of $\mathbf{1}$ under simulated biological conditions, the pore size and non-charged nature of the framework prompted us to explore the possible incorporation and posterior release of the non-conventional RAPTA-C metallodrug (estimated diameter of $0.9 \mathrm{~nm})^{15}$ in its porous structure. Indeed, impregnation of $\mathbf{1}$ with an aqueous solution of RAPTA-C $(0.025 \mathrm{M})$ leads to the rapid incorporation of this metallodrug, the equilibrium being reached after $4 \mathrm{~h}$. The dramatic decrease in $\mathrm{N}_{2}$ uptake capacity after RAPTA-C loading (Fig. 3) with maintenance of the structural integrity as evidenced by XRPD can be taken as a proof of the occupancy of the cavities by the drug (see ESI $\dagger$ ).

After this initial proof of RAPTA-C incorporation, we have studied more in detail the solid-liquid adsorption process at $298 \mathrm{~K}$. The results show a type I adsorption isotherm (Fig. 4), whose data-points have been satisfactorily fitted to the linear form of the Langmuir model (eqn (1)):

$$
C / n=C / n_{m}+1 /\left(K n_{m}\right)
$$

where $C$ is the concentration of RAPTA-C in the aqueous solution (M) at the equilibrium, $n$ is the amount of RAPTA-C incorporated in $\mathbf{1}\left(\mathrm{mmol} \mathrm{g}^{-1}\right), K$ is the Langmuir equilibrium constant and $n_{m}$ corresponds to the predicted saturation loading of RAPTA-C in $\mathbf{1}\left(\mathrm{mmol} \mathrm{g}^{-1}\right)$. The results show a maximum loading $n_{m}$ value of $2.4 \mathrm{mmol}(1.1 \mathrm{~g})$ of RAPTA-C per gram of 1 . Noteworthily, this high loading value corresponds to four RAPTA-C molecules per MOF formula unit. Taking into account the inner size ( $c a .1 .6$ and $1.0 \mathrm{~nm}$, respectively) of the octahedral and tetrahedral voids in $\mathbf{1}$, as well as the size of the RAPTA-C molecule $(0.9 \mathrm{~nm})$, we can tentatively conclude that the octahedral and tetrahedral 


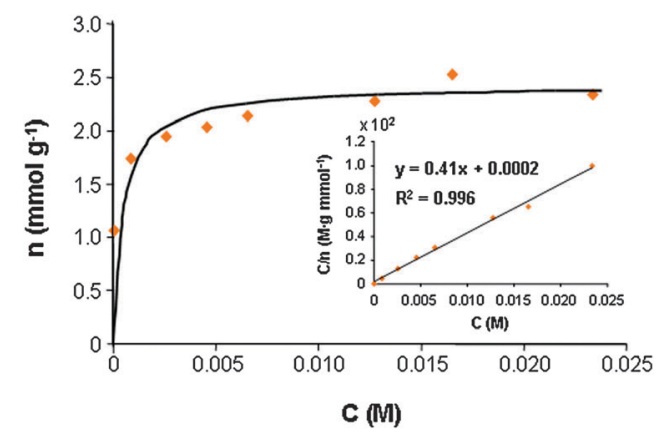

Fig. 4 Solid-liquid adsorption isotherm of an aqueous solution of RAPTA-C by 1 at $298 \mathrm{~K}$. The inset shows the linear fitting of the data to the Langmuir model.

cavities, present in a $1: 2$ ratio, host two and one RAPTA-C molecules each, respectively, to give rise to 1-RAPTA-C.

Finally, we have studied the desorption process of the loaded 1-RAPTA-C into SBF at $37^{\circ} \mathrm{C}$, in order to test the use of this system as a model for drug delivery purposes. The results show that the equilibrium of RAPTA-C release from $\mathbf{1}$. RAPTA-C is reached after 5 hours. ${ }^{16}$ The desorption data can be satisfactorily fitted with a first order kinetic model according to eqn (2):

$$
q_{\mathrm{E}}-q_{t}=q_{\mathrm{E}} \mathrm{e}^{-k t}
$$

where $q_{\mathrm{E}}$ and $q_{t}$ are the amounts of RAPTA-C released per gram of MOF $\left(\mathrm{mmol} \mathrm{g}^{-1}\right)$ at the equilibrium and at the time $t$ (h), respectively, and $k$ is the first order kinetic constant $\left(\mathrm{h}^{-1}\right)$. The fitting of the data gives rise to a $k$ value of $1.63 \mathrm{~h}^{-1}$ which corresponds to a $t_{1 / 2}$ for the release of the metallodrug, of $25 \mathrm{~min}$ (Fig. 5). This is indicative of the physisorption of the metallodrug in 1, ruling out its chemical binding, through ligand exchange reactions, to the extended $\pi$-system of diynes provided by the MOF itself. The reversibility of the adsorption process can be further stated by quantifying the amount of released drug after the equilibrium is reached (desorption branch of solid-liquid isotherm at $37^{\circ} \mathrm{C}$ ). The results show that, when $10 \mathrm{mg}$ of 1-RAPTA-C are suspended in $20 \mathrm{~mL}$ of SBF, $20 \%$ of the hosted metallodrug is released leading to a $0.1 \mathrm{mM}$ RAPTA-C solution. Noteworthily, the released amount at the equilibrium increases to $70 \%$ when the SBF volume is enlarged to $200 \mathrm{~mL}$, which corresponds to a $0.004 \mathrm{mM}$ RAPTA-C solution.

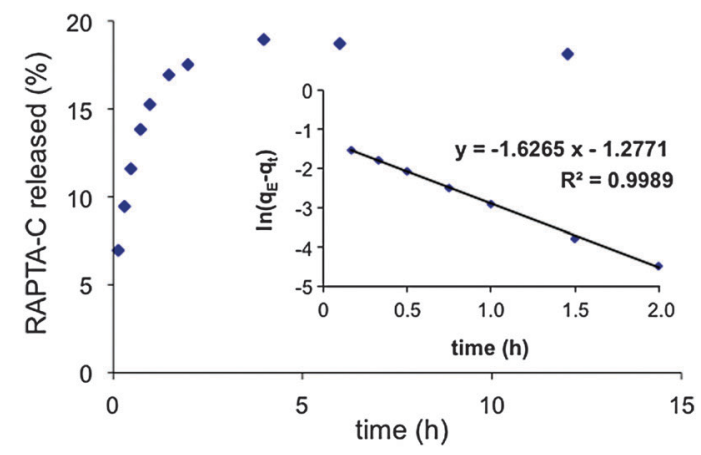

Fig. 5 Desorption process of RAPTA-C from 1-RAPTA-C (10 mg) into a simulated body fluid $(20 \mathrm{~mL})$ at $37{ }^{\circ} \mathrm{C}$. The inset shows the fitting of the data to a first order kinetic model.
In conclusion, we have obtained a novel highly porous MOF with a remarkably high thermal, mechanical and chemical stability. These features make it a model for drug delivery purposes via oral administration or transdermal patches, as demonstrated by the loading of a significant quantity of the unconventional metallodrug RAPTA-C, namely $1.1 \mathrm{~g}$ of drug per gram of MOF. Noteworthily, the adsorption process is reversible as a consequence of physisorption, RAPTA-C being easily released into simulated body fluid. All these features concur in making $\mathbf{1}$ an outstanding proof of concept for the suitability of MOFs as releasing systems for this type of non-conventional metallodrugs. Work can be anticipated in extending these intriguing results to novel MOFs based on metal ions with lower toxicity.

The authors are grateful for the generous support by the Spanish MCINN (project: CTQ2008-00037/PPQ and E. Q.-P. FPI fellowship) and Junta de Andalucía (projects: P07-FQM3213, P09-FQM-4981 and S. R. predoctoral fellowship).

\section{Notes and references}

1 A. C. McKinlay, R. E. Morris, P. Horcajada, G. Férey, R. Gref, P. Couveur and C. Serre, Angew. Chem., Int. Ed., 2010, 49, 6260; S. R. Miller, D. Heurtaux, T. Baati, P. Horcajada, J.-M. Grenèche and C. Serre, Chem. Commun., 2010, 46, 4526.

2 R. E. Morris and P. S. Wheatley, Angew. Chem., Int. Ed., 2008, 47, 4966.

3 P. Horcajada, C. Serre, M. Vallet-Regí, M. Sebban, F. Taulelle and G. Férey, Angew. Chem., Int. Ed., 2006, 45, 5974; P. Horcajada, C. Serre, G. Maurín, N. A. Ramsahye, F. Balas, M. Vallet-Regí, M. Sebban, F. Taulelle and G. Férey, J. Am. Chem. Soc., 2008, 130, 6774.

4 P. Horcajada, T. Chalati, C. Serre, B. Gillet, C. Sebrie, T. Baati, J. F. Eubank, D. Heurtaux, P. Clayette, C. Kreuz, J.-S. Chang, Y. K. Hwang, V. Marsaud, P.-N. Bories, L. Cynober, S. Gil, G. Férey, P. Couvreur and R. Gref, Nat. Mater., 2010, 9, 172.

5 I. Imaz, M. Rubio-Martínez, L. García-Fernández, F. García, D. Ruiz-Molina, J. Hernando, V. Puntes and D. Maspoch, Chem. Commun., 2010, 46, 4737.

6 W. J. Rieter, K. M. Pott, K. M. L. Taylor and W. Lin, J. Am. Chem. Soc., 2008, 130, 11584.

7 Cisplatin, Chemistry and Biochemistry of a Leading AntiCancer Drug, ed. B. Lippert, Wiley-VCH, Weinheim, 1999.

8 A. Casini, F. Edafe, M. Erlandsson, L. Gonsalvi, A. Ciancetta, N. Re, A. Ienco, L. Messori, M. Peruzzini and P. J. Dyson, Dalton Trans., 2010, 39, 5556; H. Amouri, J. Moussa, A. K. Renfrew, P. J. Dyson, M. N. Rager and L.-M. Chamoreau, Angew. Chem., Int. Ed., 2010, 49, 7530.

9 Y. K. Yan, M. Melchart, A. Habtemarian, A. F. A. Peacock and P. J. Sadler, JBIC, J. Biol. Inorg. Chem., 2006, 11, 483.

10 C. Scolaro, A. Bergamo, L. Brescacin, R. Delfino, M. Cocchietto, G. Laurenczy, T. J. Geldbach, G. Sava and P. J. Dyson, J. Med. Chem., 2005, 48, 4161.

11 T. Kokubo, H. Kushitani, C. Ohtsuki, S. Sakka and T. Yamamuro, J. Mater. Sci.: Mater. Med., 1992, 3, 79.

12 N. Masciocchi, S. Galli, V. Colombo, A. Maspero, G. Palmisano, B. Seyyedi, C. Lamberti and S. Bordiga, J. Am. Chem. Soc., 2010, 132, 7902.

13 The inner size of the cavity has been estimated as twice the distance between the centre of the cavity and the nearest atom, A, decorating its walls. The proper correction for the vdW radius of A has been applied.

14 Toxicological Profile for Nickel, August 1995, Draft Update, Agency for Toxic Substances and Disease Registry, United States Public Health Service.

15 The size of RAPTA-C has been estimated as the diameter of the equivalent sphere occupying the same volume occupied by a CCDC-derived model of the metallodrug, as calculated by SMILE (D. Eufri and A. Sironi, J. Mol. Graphics, 1989, 7, 165).

$1610 \mathrm{mg}$ of 1.RAPTA-C were suspended in $20 \mathrm{~mL}$ of SBF and the resulting suspension incubated at $37{ }^{\circ} \mathrm{C}$ with stirring. Aliquots of the supernatant solution were studied by means of UV-vis at different periods of time in order to determine the amount of released RAPTA-C. 